\title{
Maintenance and Broadening of the Ocean's Salinity Distribution by the Water Cycle
}

\author{
JAN D. ZIKA AND NiKOLAOS SKLIRIS \\ National Oceanography Centre, University of Southampton, Southampton, United Kingdom \\ A. J. George Nurser And Simon A. Josey \\ National Oceanography Centre, Southampton, United Kingdom \\ LAWRENCE MUDRYK AND FRÉDÉRIC LALIBERTÉ \\ Department of Physics, University of Toronto, Toronto, Canada \\ ROBERT MARSH \\ National Oceanography Centre, University of Southampton, Southampton, United Kingdom
}

(Manuscript received 16 April 2015, in final form 10 July 2015)

\begin{abstract}
The global water cycle leaves an imprint on ocean salinity through evaporation and precipitation. It has been proposed that observed changes in salinity can be used to infer changes in the water cycle. Here salinity is characterized by the distribution of water masses in salinity coordinates. Only mixing and sources and sinks of freshwater and salt can modify this distribution. Mixing acts to collapse the distribution, making saline waters fresher and fresh waters more saline. Hence, in steady state, there must be net precipitation over fresh waters and net evaporation over saline waters. A simple model is developed to describe the relationship between the breadth of the distribution, the water cycle, and mixing - the latter being characterized by an $e$-folding time scale. In both observations and a state-of-the-art ocean model, the water cycle maintains a salinity distribution in steady state with a mixing time scale of the order of $50 \mathrm{yr}$. The same simple model predicts the response of the salinity distribution to a change in the water cycle. This study suggests that observations of changes in ocean salinity could be used to infer changes in the hydrological cycle.
\end{abstract}

\section{Introduction}

The hydrological cycle is a central component of the global climate system, linking ocean, land, and atmosphere. As the climate warms, the capacity for the atmosphere to store moisture increases. This increase in moisture content is described, assuming constant relative humidity, by the Clausius-Clapeyron relationship (Peixoto and Oort 1992). With atmospheric circulation held constant, such an increase in moisture content leads to increases in the strength of evaporation and precipitation - that is, an amplification of the hydrological

Corresponding author address: Jan D. Zika, National Oceanography Centre, University of Southampton, European Way, Southampton SO14 3ZH, United Kingdom.

E-mail: j.d.zika@soton.ac.uk cycle. It has been suggested, however, that with warming may come a weakening of the atmospheric circulation, leading to a partial compensation for the increase in the hydrological cycle (e.g., Held and Soden 2006). A change in the hydrological cycle below that predicted by Clausius-Clapeyron was exhibited by the majority of earth system models (ESMs) from the IPCC Third and Fourth Assessment Reports (AR3 and AR4, respectively; Held and Soden 2006; Durack et al. 2012). However, uncertainty in directly estimating changes in the hydrological cycle remains a long-standing problem.

Changes in the hydrological cycle are notoriously hard to measure, with the lack of robust estimates of rainfall and evaporation over the ocean (and their concomitant latent heating/cooling) being of particular concern (e.g., Trenberth et al. 2007; Schanze et al. 2010). There are also major problems when assessing the global hydrological 
cycle and its variability from reanalysis products, which often violate basic physical constraints and are inconsistent with observational estimates (Trenberth et al. 2011).

With the ocean receiving over $80 \%$ of the total global rainfall (Schanze et al. 2010), oceanic observations of salinity offer a unique opportunity in terms of measuring the integrated effect of changes in the hydrological cycle (Trenberth et al. 2007). Only recently, however, has the observational network expanded to the point where the mean state and trends in upper-ocean salinity can be robustly estimated. This is thanks to historical and ongoing ship-based hydrographic measurements and now the Argo observing programs, allowing the quantification of the global salinity change (Hosoda et al. 2009; Helm et al. 2010; Durack et al. 2012; Skliris et al. 2014). Durack et al. (2012), using an empirical measure of ocean surface salinity change, found a hydrological cycle change over and above that predicted by the majority of ESMs from the AR3 framework and phase 3 of CMIP (CMIP3).

In this study we will use the water-mass transformation framework of Walin (1982) to understand the relationship between the salinity distribution of the ocean, the water cycle, and mixing, and we will use this framework to motivate a simple model for that distribution, involving just one parameter-a mixing time scale-to represent the transient response of ocean salinity to changes in the water cycle.

\section{The relationship between the salinity distribution, freshwater fluxes, and mixing}

In Walin's $(1977,1982)$ seminal papers, the ocean circulation problem is posed in a framework following water masses defined by a particular tracer rather than in fixed geographical (Eulerian) coordinates. Flow in watermass coordinates can be driven only by processes that can modify a water parcel's tracer concentration and thus cause a net transport from one water-mass class to another (Zika et al. 2012; Groeskamp et al. 2014). For conserved tracers without interior sources, this modification of concentration can be achieved only by diffusive flux convergence or by surface fluxes-either directly by fluxes of the tracer or by dilution/concentration resulting from freshwater fluxes (Hieronymus et al. 2014; Evans et al. 2014).

We apply the water-mass transformation framework using salinity $(S$; the salt fraction by mass of a fluid parcel, defined in units of grams per kilogram) as the tracer coordinate. In terms of observations, absolute salinity is conserved almost exactly (McDougall et al. 2009). We assume there are no exchanges of salt with the solid earth. For simplicity we make the Boussinesq approximation substituting conservation of mass for conservation of volume and take the salinity in units of grams per kilogram of seawater to be equivalent to kilograms per cubic meter, although these assumptions can in fact be relaxed quite simply. Here we will consider the realistic case where surface fluxes of freshwater change the volume of water in the ocean. In appendix A we will consider the case where the ocean volume is fixed and freshwater fluxes are approximated with an equivalent salt flux as is common in ocean models.

\section{a. Volume balance}

The volume of water with salinity less than $S^{*}$ (Fig. 1) is given by

$$
V\left(S^{*}\right)=\iiint_{S<S^{*}} d x d y d z,
$$

and the volume of water per salinity interval (analogous to the probability density function) is given by

$$
\frac{\partial V}{\partial S}\left(S^{*}\right)=\lim _{\Delta S \rightarrow 0} \frac{1}{\Delta S} \iiint_{S^{*}<S<S^{*}+\Delta S} d x d y d z .
$$

The profile of $\partial V / \partial S$ then gives the relative volumes of water of different salinities-that is, the water-mass distribution in terms of salinity.

The surface freshwater input is $P-E+R$, where $P$ is precipitation (including melting ice), $E$ is evaporation (including ice formation), and $R$ is river runoff.

The volume of water fresher than $S^{*} V\left(S^{*}\right)$ increases because of the surface input of freshwater everywhere where the sea surface salinity SSS is less than $S^{*}$ such that

$$
F_{w}\left(S^{*}\right)=\iint_{\mathrm{SSS}<S^{*}} P-E+R d x d y
$$

and decreases because of the volume flux $G\left(S^{*}\right)$ across the $S=S^{*}$ surface from lower to higher salinity (often called the transformation rate; Fig. 1). Hence the rate of change of $V\left(S^{*}\right)$ is given by

$$
\frac{d V\left(S^{*}\right)}{d t}=F_{w}\left(S^{*}\right)-G\left(S^{*}\right)
$$

\section{b. Salt balance}

Consider now the salt contained within the volume $V\left(S^{*}\right)$ (see Fig. 1a):

$$
\begin{aligned}
\mathbb{S}\left(S^{*}\right) & =\iiint_{S<S^{*}} S d x d y d z \\
& =\int_{0}^{S^{*}} S \frac{\partial V}{\partial S} d S .
\end{aligned}
$$

The value $d \mathbb{S}\left(S^{*}\right) / d t$, the rate of change of the salt contained within $V\left(S^{*}\right)$, is simply the sum of the 


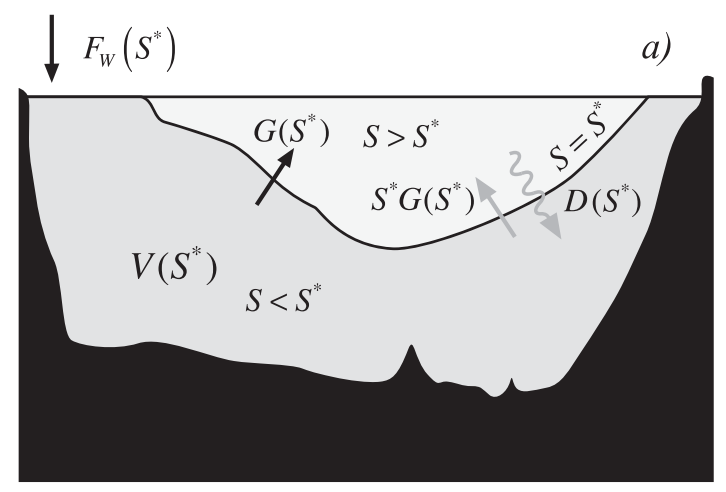

c)

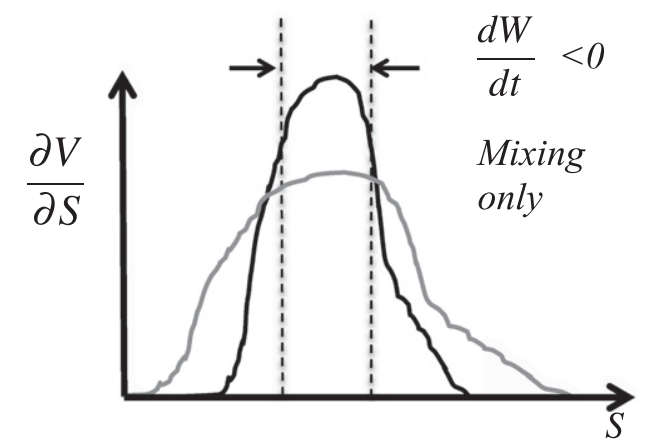

b)

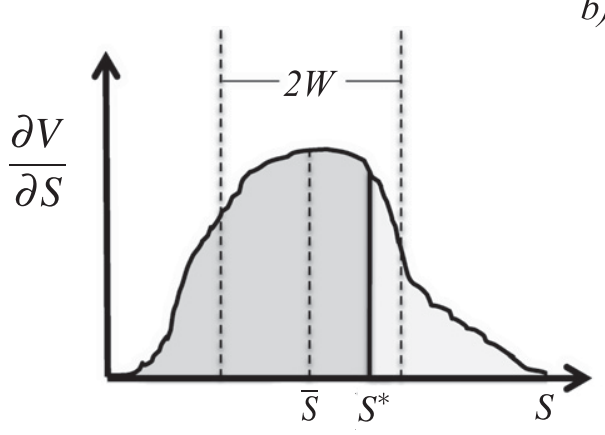

d)

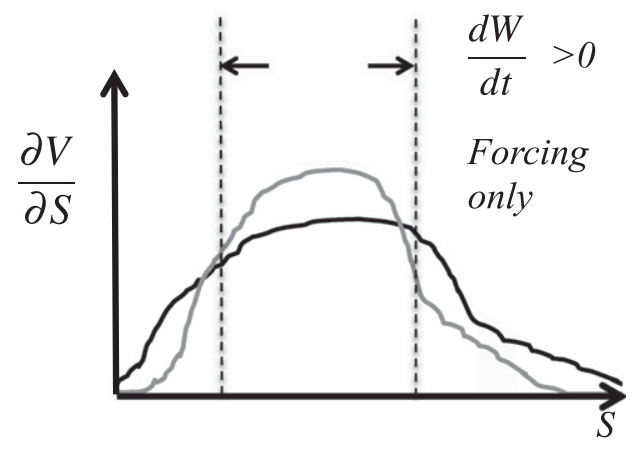

FIG. 1. (a) Schematic cross section through the ocean, where precipitation is applied as a volume flux. The volume $V\left(S^{*}\right)$ of relatively fresh water with $S<S^{*}$ is shaded dark gray, and the saltier water with $S>S^{*}$ is shaded light gray. Volume fluxes are indicated by the black arrows and salinity fluxes by the gray arrows. (b) Corresponding schematic for the distribution of volume of seawater in salinity coordinates $(\partial V / \partial S)$ whose integral from $S=0$ to $S=S^{*}$ is $V\left(S^{*}\right)$ (the dark gray area). Shown are typical locations of the mean salinity $\bar{S}$ and twice the mean deviation in salinity $2 W$. (c),(d) Schematics showing how mixing and the hydrological cycle affect the volumetric distribution. (c) Mixing always acts to homogenize salinity, making the distribution narrower (reducing $W$ ). (d) To achieve a steady state, the hydrological cycle must make the distribution broader through net evaporation over high-salinity regions and net precipitation over low-salinity regions (increasing $W$ ).

advective and diffusive salt fluxes into $V\left(S^{*}\right)$ across the $S^{*}$ isohaline:

$$
\frac{d \mathbb{S}\left(S^{*}\right)}{d t}=-S^{*} G\left(S^{*}\right)+D\left(S^{*}\right)
$$

Here we choose the natural sign convention for the diffusive salt flux $D$ such that it is positive in the direction of decreasing $S$ (the reverse of that used for the volume flux $G$ ).

If we assume that diffusion of salt is related to the local salinity gradient and a diffusion tensor $\mathbf{K}$, then

$$
D=\iint_{S=S^{*}} \nabla S \cdot \mathbf{K} \cdot \nabla S|\nabla S|^{-1} d A>0,
$$

where the positive sign comes from the assumed positive definiteness of the diffusion tensor that ensures $\nabla S \cdot \mathbf{K} \cdot \nabla S>0$. The positive sign of $D$ then ensures that the diffusive salt flux is always down the salinity gradient and in particular that it always extracts salt from the region with $S>S^{*}$ and is a source of salt for the region $V\left(S^{*}\right)$ where $S<S^{*}$ in $(6)$.

Combining (4), (6), and (7), it follows that

$$
\begin{aligned}
\frac{d \mathbb{S}\left(S^{*}\right)}{d t}= & -S^{*}\left[F_{w}\left(S^{*}\right)-\frac{d V\left(S^{*}\right)}{d t}\right] \\
& +\iint_{S=S^{*}} \nabla S \cdot \mathbf{K} \cdot \nabla S|\nabla S|^{-1} d A .
\end{aligned}
$$

In the case where $P-E+R$ is represented as a salt flux rather than a freshwater flux, as discussed in appendix A, (8) is replaced with this nearly identical equation:

$$
\begin{aligned}
\frac{d \mathbb{S}\left(S^{*}\right)}{d t}= & -S_{0} F_{w}\left(S^{*}\right)-S^{*} \frac{d V\left(S^{*}\right)}{d t} \\
& +\iint_{S=S^{*}} \nabla S \cdot \mathbf{K} \cdot \nabla S|\nabla S|^{-1} d A,
\end{aligned}
$$

where $S_{0}$ is an arbitrary reference salinity commonly chosen to be the global-mean salinity $\bar{S}$. 
In steady state, (8) reduces to a balance between diffusion into the fresher waters with $S<S^{*}$ and the advective outflow of salt through the $S^{*}$ isohaline, which, since the volume $V\left(S^{*}\right)$ is constant, is from (4) simply the surface inflow $F_{w}\left(S^{*}\right)$ times $S^{*}$ such that

$$
S^{*} F_{w}\left(S^{*}\right)=\iint_{S=S^{*}} \nabla S \cdot \mathbf{K} \cdot \nabla S|\nabla S|^{-1} d A>0 .
$$

To maintain the salinity distribution in steady state, there must be net rainfall and river runoff over the freshest water masses and net evaporation over the more saline waters (Fig. 1d). The water cycle must maintain the contrast in water masses, constantly making saline waters more saline and fresh waters more fresh, as mixing can do only the opposite. If the water cycle were to switch off completely (i.e., $P-E+R \equiv 0$ everywhere), the salinity distribution would collapse toward a single delta function centered on the present global-mean salinity $\bar{S}$ (Fig. 1c).

As $F_{w}$, the accumulated integral of $P-E+R$, maintains the salinity distribution in steady state, we choose this as our definition of the water cycle for the purposes of this study. In the next section we will formulate a simple model for the relationship between the width of distribution and the accumulated $P-E+R$ up to the mean salinity $\bar{S}, F_{w}(\bar{S})$.

\section{A simple model for the width of the salinity distribution}

We now develop a simple model for the mean deviation of salinity (a measure of the half-width of the distribution). The mean deviation $W$ is defined here as the volume-weighted mean absolute deviation from the global-mean salinity $\bar{S}$ :

$$
W=\frac{1}{V_{0}} \iiint|S-\bar{S}| d x d y d z,
$$

where $V_{0}$ is the volume of the global ocean.

Given that the mean salinity $\bar{S}$ is defined by

$$
\iiint(S-\bar{S}) d x d y d z=0
$$

we rewrite $W$ as

$$
W=\frac{2}{V_{0}} \iiint_{S<\bar{S}}(\bar{S}-S) d x d y d z .
$$

Substituting (1) and (5), it follows that

$$
W=\frac{2}{V_{0}}[\bar{S} V(\bar{S})-\mathbb{S}(\bar{S})] .
$$

We now consider $d W / d t$, the rate of change of the mean deviation; assuming that the total volume of the ocean does not change (which implies that the mean salinity does not change) and then substituting (8) [or identically (9) when $S_{0}=\bar{S}$ ] yields

$$
\frac{d W}{d t}=\frac{2 \bar{S}}{V_{0}} F_{w}(\bar{S})-\frac{2}{V_{0}} D(\bar{S}) .
$$

The above result links the rate of change of the mean deviation $W$ simply to the accumulated precipitation $F_{w}(\bar{S})$ into waters fresher than $\bar{S}$ and to the diffusive salinity flux across the $\bar{S}$ isohaline $D(\bar{S})$. In appendix B we derive (14) in the case where the total volume of the ocean changes.

In practice, the diffusive salinity flux is unknown. A plausible assumption is that the diffusive term above is proportional to the width of the distribution itself such that

$$
\frac{2}{V_{0}} D(\bar{S})=\frac{1}{\tau} W
$$

where $\tau$ is a mixing time scale. In this case (14) takes the following form:

$$
\frac{d W}{d t}=\frac{2 \bar{S}}{V_{0}} F_{w}(\bar{S})-\frac{1}{\tau} W .
$$

We now explain our argument for the scaling of the mixing term in (15). As $W$ increases, the contrast between water masses becomes larger and hence we expect $|\nabla S|$ to increase also. Let us assume that the ocean is divided into two regions with salinities $\bar{S}-\Delta S$ and $\bar{S}+\Delta S$, with their centers separated by a distance $X$ and with an interface connecting the two regions of area $Y^{2}$ such that the total volume is $2 Y^{2} X$. For our purposes it does not matter if the two regions are separated in the vertical or horizontal directions (in reality it is some combination of the two). Applying these scales to (11) yields

$$
W \rightarrow 2 Y^{2} X \Delta S / 2 Y^{2} X=\Delta S,
$$

and the mixing term in (7) scales to

$$
D(\bar{S}) \rightarrow K \frac{2 \Delta S}{X} Y^{2}=K \frac{\Delta S}{X^{2}} V_{0} .
$$

Then by (15) and (17),

$$
\tau=\frac{X^{2}}{2 K}
$$

Since we expect $K$ to be a constant we may expect $\tau$ to also be a constant. Rather than choosing a scale $X$ and defining an arbitrary mixing coefficient $K$, we will simply describe the mixing term with the time scale $\tau$. A solution for the change in the mean deviation $W^{\prime}$ for a step change in the water cycle of $F_{w}^{\prime}$ is 


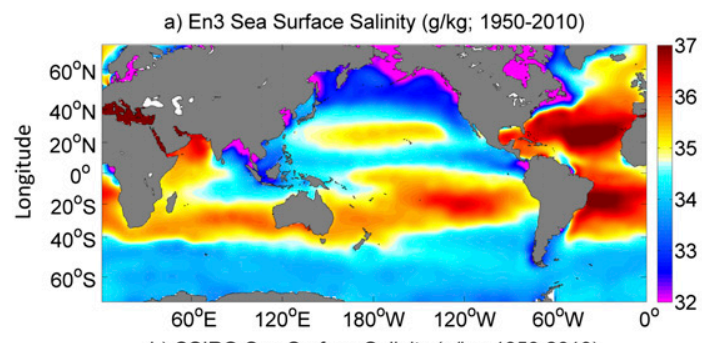

b) CSIRO Sea Surface Salinity (g/kg; 1950-2010)

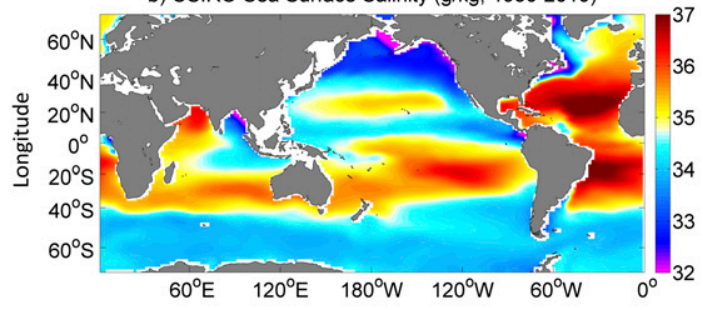

c) CCSM4 Sea Surface Salinity (g/kg; 1950-2010)

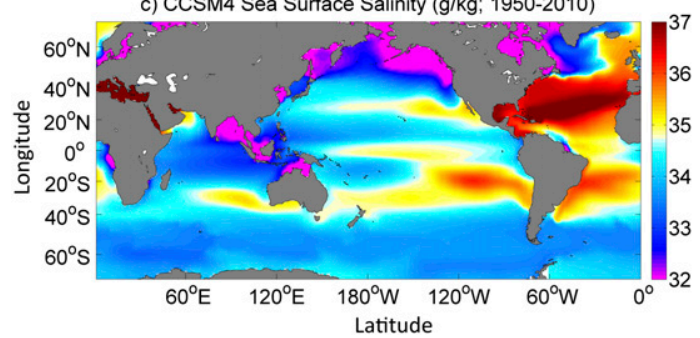

d) CORE2 E-P-R (m/yr; 1950-2010)

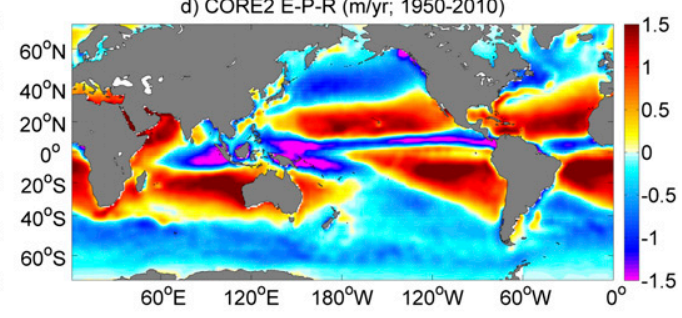

e) OAFLUX-GPCP E-P-R (m/yr; 1979-2010)

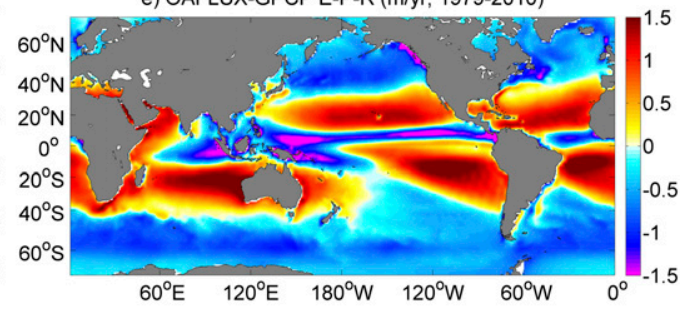

f) CCSM4 E-P-R (m/yr; 1950-2010)

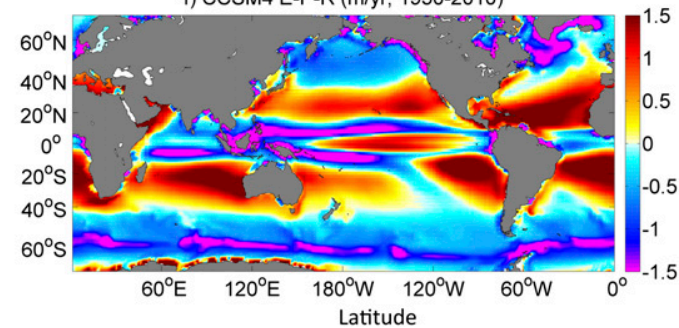

FIG. 2. (a),(b),(c) Historical-mean SSS $\left(\mathrm{g} \mathrm{kg}^{-1}\right)$ and (d),(e),(f) evaporation minus precipitation minus river runoff $\left(E-P-R ; \mathrm{m} \mathrm{yr}^{-1}\right)$ : (a) EN3 SSS (1950-2010), (b) CSIRO SSS (1950-2010), (c) CCSM4 SSS (1950-2010), (d) CORE2 $E-P-R$ (1950-2006), (e) OAFlux-GPCP $E-P-R$ (1979-2010), and (f) CCSM4 $E-P-R$ (1950-2010). Note that $E-P-R=-(P-E+R)$.

$$
W^{\prime}=\frac{2 \bar{S}}{V_{0}} \tau F_{w}^{\prime}\left(1-e^{-t / \tau}\right)
$$

Thus, the mixing parameter $\tau$ is an $e$-folding time scale describing the salinity distribution's response to a change in the hydrological cycle.

If all the mixing were achieved by a vertical mixing coefficient of $10^{-5} \mathrm{~m}^{2} \mathrm{~s}^{-1}$ over a vertical distance of $200 \mathrm{~m}$, we would expect a mixing time scale of $65 \mathrm{yr}$. Hieronymus et al. (2014) have shown that both isopycnal and diapycnal mixing maintain the salinity distribution in steady state, so we expect that considering only one component will yield an overestimate. Indeed, it may be that a different time scale maintains $W$ in steady state from that which sets the response of $W$ to small perturbations. These two regimes may be set by different mixing processes. However, as the salinity distribution changes with time, we expect the geographical structure of that distribution to change slowly, implying that $\tau$ could be a general parameter defining a wide range of perturbations to the current mean state.

Equation (16) can be integrated in time to show the relationship between the accumulated change in the water cycle $\int F_{w}^{\prime}(\bar{S}) d t$ and changes in the width of the salinity distribution $W^{\prime}$ such that

$$
\int F_{w}^{\prime}(\bar{S}) d t=\frac{V_{0}}{2 \bar{S}}\left(W^{\prime}+\frac{1}{\tau} \int W^{\prime} d t\right),
$$

where $F_{w}^{\prime}$ and $W^{\prime}$ are deviations from a long-term mean in steady state. In (20) the first term on the right-hand side represents the total amount of freshwater transported from regions where $S>\bar{S}$ to regions where $S<\bar{S}$, while the second term removes the predicted effect of mixing. In the following sections we will use both numerical models and observations to test the validity of (16) and (20) and estimate $\tau$ and the temporal scales over which it is a relevant quantity.

\section{Observational and model data}

\section{a. Hydrographic data}

Here two observational datasets for ocean salinity are used: 1$)$ the Met Office EN3v2a dataset $\left(1^{\circ} \times 1^{\circ}\right.$ grid) (http:// www.metoffice.gov.uk/hadobs/en3), an update of the EN2 dataset described in Ingleby and Huddleston (2007) (Fig. 2a), 
and 2) the CSIRO dataset $\left(1^{\circ} \times 2^{\circ}\right.$ latitude-longitude grid) developed by Durack and Wijffels (2010) (Fig. 2b). Both datasets consist of quality-controlled temperature and salinity (PSS-78) profiles spanning the period 1950 2010 with most of the original data sources being widely available, including the World Ocean Database 2005 (Boyer et al. 2006), the Global Temperature and Salinity Profile Programme (from 1990; Wilson 1998), and profiling float data from the Argo Global Data Assembly Center (from 1999; www.argo.ucsd.edu). In general, observational coverage of salinity data strongly increases over the 1950-2010 period for both the near-surface and deep layers. There is a relatively sparse coverage in the early decades, particularly in the Southern Hemisphere and at depths greater than $1000 \mathrm{~m}$, improving to almost global coverage from the surface to 2000-m depth after the introduction of the Argo floats (Durack and Wijffels 2010; Skliris et al. 2014).

\section{b. $P-E+R$ data}

Schanze et al. (2010) considered the global freshwater budget across eight different surface flux products and found a range in their ability to achieve budget closure. Two combined atmospheric reanalysis/observational global ocean $P-E+R$ datasets are included in the present study to assess the climatological-mean global freshwater cycle in salinity space. Each was found by Schanze et al. (2010) to close the budget to within 0.5 Sverdrups $\left(\mathrm{Sv} ; 1 \mathrm{~Sv} \equiv 10^{6} \mathrm{~m}^{3} \mathrm{~s}^{-1}\right)$. They are as follows:

1) Objectively analyzed air-sea fluxes (OAFlux)/ Global Precipitation Climatology Project (GPCP). This is a hybrid product in which $E$ is provided by the OAFlux dataset (Yu and Weller 2007; fields extracted for the period 1979-2010), which blends NCEP and ERA-40 reanalysis products with satellite surface meteorology through an objective synthesis; $P$ is obtained from GPCP v2.2 (Huffman et al. 2009); and $R$ is based on recent estimates from Dai and Trenberth (2002) and Dai et al. (2009) (OAGP-Dai hereafter; Fig. 2c). The runoff $R$ includes river runoff, which gives a global-mean river freshwater discharge of $1.18 \mathrm{~Sv}$, and the ice-melting flux from Antarctica (0.06 Sv) and Greenland (0.01 Sv). Schanze et al. (2010) noted that this dataset is based on stateof-the-art products but concluded nevertheless that the errors in the $E$ and $P$ terms remain at the $10 \%$ level and find a net imbalance in the global oceanic freshwater cycle of $0.46 \mathrm{~Sv}$.

2) Co-ordinated Ocean-Ice Reference Experiments, version 2 (COREv2). The second product considered is the COREv2 $P-E$ dataset spanning the period 1979-2006 (Large and Yeager 2009) combined with the $R$ product from Dai et al. (2009) described above (CORE2-Dai hereafter; Fig. 2d). The $E$ field is based on the NCEP-NCAR reanalysis with various adjustments, and the $P$ field is a blend of precipitation products including GPCP and the CPC Merged Analysis of Precipitation (CMAP; Xie and Arkin 1997) datasets, both based on rain gauge observations and satellite retrievals. Schanze et al. (2010) find that CORE2-Dai has a smaller net imbalance $(-0.14 \mathrm{~Sv})$ than OAGP-Dai and is the closest of the products they consider to achieving global closure.

\section{c. Model data}

Here we use the Community Climate System Model version 4 (CCSM4), which contains the Community Atmosphere Model version 4 (CAM4), the Community Land Model version 4 (CLM4), the Community Ice Code version 4 (CICE4), and the Parallel Ocean Program version 2 (POP2) (see Gent et al. 2011; http://www. cesm.ucar.edu/). The atmosphere and land model are run on a nominally $2^{\circ}$ finite volume grid, while the ocean and ice models are run on the nominally $1^{\circ}$ Greenland dipole grid. The configuration is identical to the "coupled model" configuration described in Mudryk et al. (2014). CCSM4 simulates freshwater fluxes at the ocean surface as equivalent salt fluxes of the form $-S_{0}(P-$ $E+R)$ (Fig. 2e).

The model was initialized from the 500th year of the standard $2^{\circ}$ CCSM4 preindustrial (1850) control simulation and run for an additional $375 \mathrm{yr}$ with continued preindustrial forcing. We analyze the final $30 \mathrm{yr}$ of this simulation. From year 345 of the control simulation, a second simulation was initialized, forced by timedependent estimates of historical greenhouse gases, ozone, aerosols, volcanic emissions, and solar variability from 1850 to 2005 . This second simulation was continued until 2100 using radiative forcing from the $4.5 \mathrm{~W} \mathrm{~m}^{-2}$ representative concentration pathway (RCP4.5). The data for these prescriptions are the standard datasets provided by NCAR and are consistent with the preindustrial, historical climate and future projection scenarios outlined for the CMIP5 protocol (Taylor et al. 2012).

\section{Results}

\section{a. Mean balance}

The water-mass transformation framework described above is applied to the EN3 and CSIRO observational salinity datasets over 1950-2010 and to the CCSM4 preindustrial control and historical run data to calculate the mean ocean volumetric distribution in salinity coordinates. Figure $3 \mathrm{a}$ shows the global ocean mean 

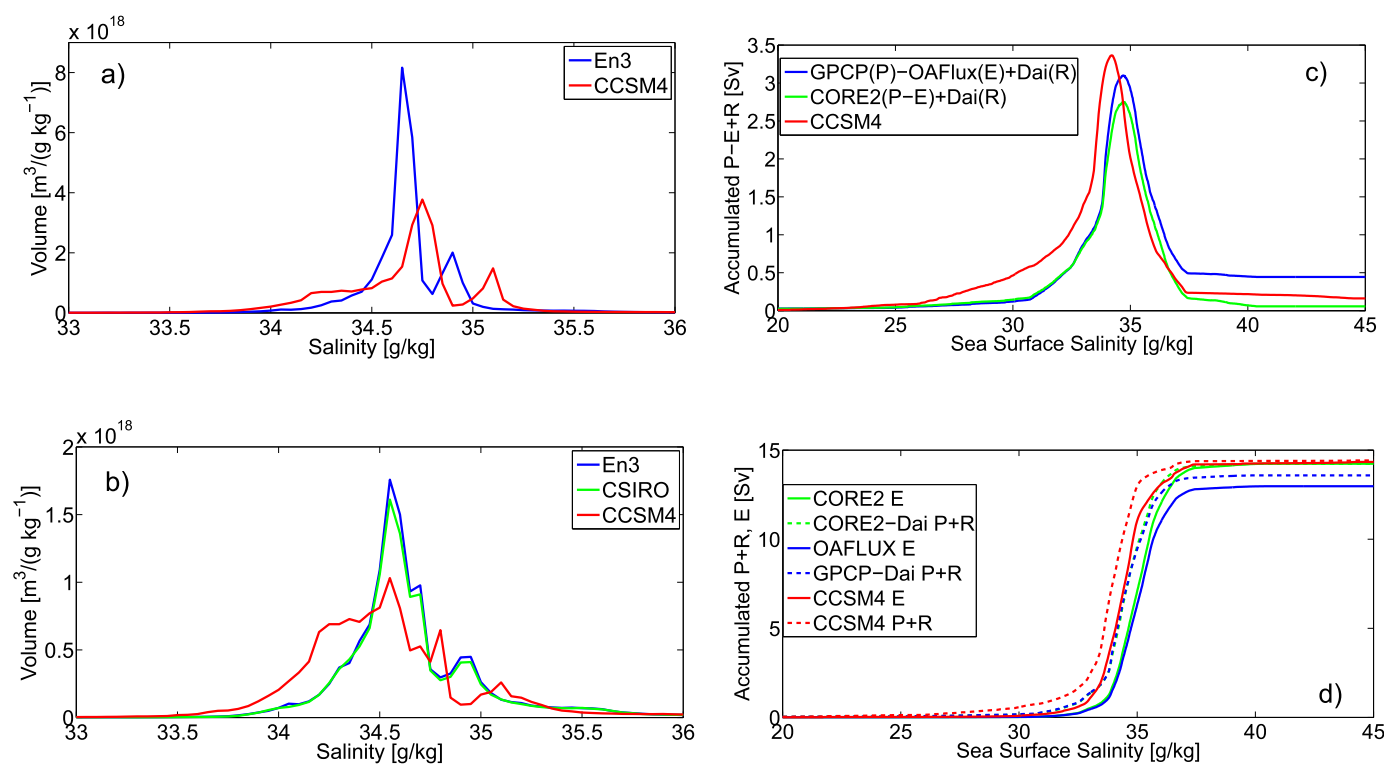

FIG. 3. (a),(b) Mean volumetric distribution $\partial V / \partial S\left[\mathrm{~m}^{3}\left(\mathrm{~g} \mathrm{~kg}^{-1}\right)^{-1}\right]$ in salinity coordinates over 1950-2010. (a) Total depth: EN3 (blue), CCSM4 (red). (b) 0-2000-m depth: EN3 (blue), CSIRO (green), and CCSM4 (red). (c),(d) Historicalmean accumulated freshwater fluxes (Sv) in SSS coordinates for OAGP-Dai (blue), CORE2-Dai (green), and CCSM4 (red) datasets: (c) $P-E+R$, (d) $E$ (solid), and $P+R$ (dashed).

volumetric distribution $\partial V / \partial S$ [the volume of seawater per unit salinity; $\left.\mathrm{m}^{3}\left(\mathrm{~g} \mathrm{~kg}^{-1}\right)^{-1}\right]$ in $0.05 \mathrm{~g} \mathrm{~kg}^{-1}$ salinity bins for the EN3 and CCSM4 datasets. Figure 3b shows $\partial V / \partial S$ for all three datasets but for the limited area and depth set by the CSIRO dataset's geographical configuration (i.e., the ocean deeper than $2000 \mathrm{~m}$, regions of the ocean where the sea floor is shallower than $1000 \mathrm{~m}$, and all marginal seas are excluded; see white areas in Fig. 2b). The volumetric distribution shows two distinct peaks, with the smaller one at higher salinity corresponding to the Atlantic Ocean (this two-mode structure is discussed further in section 6). The larger peak is at higher salinities in CCSM4 as compared to observations. The CCSM4 preindustrial control run also shows a broader mean volumetric distribution than the observations, with a mean deviation $W$ of $0.284( \pm 0.0003)$ as compared to $0.192( \pm 0.0014)$ in EN3. In the CCSM4 historical run (1950-2010) mean $W$ is slightly higher at $0.290( \pm 0.0020)$. The mean volumetric distributions for the upper-2000-m layer of the two observationally based datasets are very close (EN3: $W=0.271$; CSIRO: $W=$ 0.273), whereas again CCSM4 shows a broader volumetric distribution [preindustrial control run: $W=0.375$ $( \pm 0.0005)$; historical run: $W=0.382( \pm 0.002)]$.

To estimate the water cycle amplitude in our watermass transformation framework, we integrate the climatological annual-mean $P-E+R$ flux in the climatological annual-mean SSS space (from low to high salinity). We use the CCSM4 model preindustrial control and historical run outputs and the two observation-/reanalysis-based $P-E+R$ products (CORE2Dai and OAGP-Dai). Figure $3 \mathrm{c}$ shows the accumulated integral of $P-E+R$ in salinity space $\left(0.05 \mathrm{~g} \mathrm{~kg}^{-2}\right.$ bins $)$ for CCSM4 and for the two observation-/reanalysisbased products integrated in the EN3-derived SSS space. We should note here that what we term SSS for the CCSM4 and EN3 datasets should actually be referred to as near-surface salinity since the upper vertical level for both datasets is located at 5-m depth.

The peak in $F_{w}$ separates the regions dominated by precipitation plus runoff $(P+R>E)$ from the evaporation-dominated regions $(E>P+R)$ in surface salinity space. If the global annual-mean freshwater budget is balanced, the total $P-E+R$ must sum to zero (such that the ocean is not gaining volume), and hence $F_{w}$ should be zero at the salinity maximum $\left[F_{w}\left(S_{\max }\right)=0\right]$. For CORE2-Dai the global freshwater budget is very close to being in balance with a value of $0.05 \mathrm{~Sv}$ [note that this is slightly different from the value of $-0.14 \mathrm{~Sv}$ found by Schanze et al. (2010) because of slight variations in the land mask and period employed]. For the OAGP-Dai dataset a value of $0.44 \mathrm{~Sv}$ is obtained, which is indicative of a significant global net freshening $(E<$ $P+R)$ consistent with the results of Schanze et al. (2010). The relative contributions to the imbalance from $E$ and $P$ separately are also shown (Fig. 3d). We speculate that the major source of uncertainty is the $E$ term, as the gap between integrated $E$ for the two products is 
larger than that for $P$ by nearly a factor of 2 . OAGP-Dai has a significantly smaller integrated contribution from $E$ than $P$. This underestimate of $E$ in OAGP-Dai is consistent with our understanding of the heat budget, which is related to the freshwater budget through the equivalence of evaporation with the latent heat flux. OAFlux is unable to close the global ocean heat budget when combined with satellite radiative flux datasets, having a large global-mean net heat flux imbalance of the order of $30 \mathrm{~W} \mathrm{~m}^{-2}$, whereas COREv2 is closed to within $2 \mathrm{~W} \mathrm{~m}^{-2}$ (Josey et al. 2013). It is likely that latent heat flux underestimation plays a significant role in this imbalance and that the increase in $E$ required to achieve freshwater budget closure indicated by our results would also contribute a significant amount toward the heat budget imbalance. In accordance with the steady theory discussed above, the water cycle amplitude is defined here as $F_{w}(\bar{S})$. This gives a mean water cycle amplitude of $2.70 \mathrm{~Sv}$ for CORE2-Dai and 2.65 Sv for OAGP-Dai.

The mean global water cycle in the CCSM4 historical run (1950-2010) is close to balanced, showing a small global net freshening of $0.1 \mathrm{~Sv}$. The water cycle amplitude is $3.17 \pm 0.11 \mathrm{~Sv}$ for the preindustrial control and $3.22 \pm 0.14 \mathrm{~Sv}$ for the historical run, which is considerably larger than in the observations. As discussed above, the water cycle acts to stretch the volumetric distribution maintaining the contrast between water masses (i.e., making saline waters more saline and fresh waters fresher), while mixing acts to collapse the distribution, homogenizing salinity (i.e., making saline waters fresher and fresh waters more saline), with the two contributions balancing each other at steady state. Hence, the broader salinity volumetric distribution may reflect the higher water cycle strength in CCSM4 as compared to observations.

Using the above estimates of $F_{w}(\bar{S})$ and the mean deviation of the salinity distribution $W$, we estimate the mixing time-scale $\tau$, setting the steady (or quasi steady) state balance from (13) taking $d W / d t=0$. Considering the total ocean volume, we get a mean $\tau$ of $48.3 \pm 0.8 \mathrm{yr}$ for EN3 and $54.1 \pm 0.7(54.5 \pm 0.9) \mathrm{yr}$ for the CCSM4 preindustrial control (historical) run. Considering only the upper-2000-m layer and excluding coastal areas and marginal seas to match the CSIRO configuration, we get a mean $\tau$ of $30.1 \pm 0.6 \mathrm{yr}$ for EN3, 29.6 $\pm 0.7 \mathrm{yr}$ for CSIRO, and $35.1 \pm 0.5(35.5 \pm 0.8)$ yr for CCSM4 for the preindustrial control (historical) runs.

\section{b. Transient response}

In both the model and the observations the water cycle maintains the global ocean salinity volumetric distribution in steady state with a mixing time scale of the order of $50 \mathrm{yr}$. We may now use the same simple
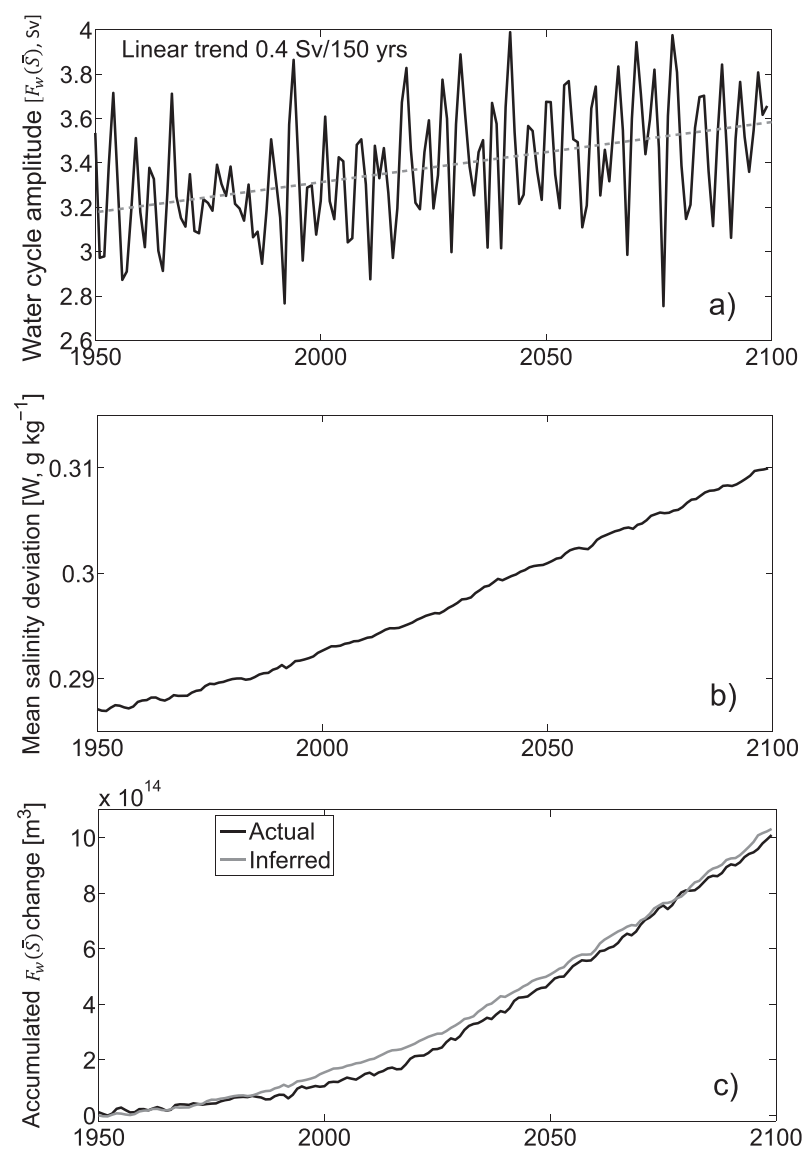

FIG. 4. Water cycle change in the CCSM4 1950-2100 run (historical period 1950-2010 + RCP4.5 scenario 2010-2100). (a) Yearly (black) and long-term (gray dashed) trend of the integrated $P-E+R$ over regions where SSS $<\bar{S}\left[F_{w}(\bar{S})\right.$; Sv]. (b) Mean deviation of salinity distribution $W\left(\mathrm{~g} \mathrm{~kg}^{-1}\right)$. (c) Accumulated freshwater transport from high-salinity to low-salinity regions by the water cycle $\int F_{w}^{\prime} d t$. In (c) the black line is the true accumulated change in the simulation, and the gray line is the change inferred based on (20) using a mixing time-scale $\tau$ of $54 \mathrm{yr}$ and assuming $W$ has changed linearly up to the year where $\int F_{w}^{\prime} d t$ is inferred.

model [see (20)] to relate the response of the salinity distribution to a change in the water cycle.

Figure 4a shows time variations of the water cycle amplitude $F_{w}(\bar{S})$ in CCSM4 over 1950-2100 (historical period 1950-2010 + RCP4.5 scenario 2010-2100). Although interannual variability is strong, the water cycle increases in amplitude by approximately $0.4 \mathrm{~Sv}(100 \mathrm{yr})^{-1}$ (statistically significant at the $95 \%$ confidence interval), which corresponds to an amplification of the water cycle of $12.5 \%$. Considering only the historical period (19502010) results indicates a small water cycle amplification of $2.5 \%$ (not statistically significant at the $95 \%$ confidence interval). The value $W$ increases quasilinearly from the early $2000 \mathrm{~s}(W \approx 0.29)$ to the end of the twenty-first century $(W \approx 0.31)$, which is consistent 
with a stretching of the salinity volumetric distribution driven by an amplification of the water cycle (Fig. 4b).

Figure $4 \mathrm{c}$ shows the accumulated integral of the extra volume added to (extracted from) the surface of fresh (saline) regions by the changing water cycle $\left[\int F_{w}^{\prime} d t\right.$, where $F_{w}^{\prime}$ is the anomaly of $F_{w}(\bar{S})$ with respect to 1950]. The time series for $\int F_{w}^{\prime} d t$ and $W$ diverges after the early 2000s, with the difference in the slopes of the two curves corresponding to the contribution of the accumulated change in the diffusive flux across the $S=\bar{S}$ isosurface [as defined in (7)]. As the water cycle amplifies, $W$ increases and the salinity contrast between water masses becomes larger, resulting in an increasing salinity diffusive flux. The latter produces a relative damping of the isohaline volumetric distribution, hence acting in the opposite direction of the increasing surface freshwater flux. The progressive increase in salt mixing over that period has reduced the net stretching of the salinity distribution (i.e., driven by the water cycle increase) by approximately $60 \%$ at the end of the twenty-first century. The gray curve in Fig. 4 shows $\int F_{w}^{\prime} d t$ as predicted by (20) assuming a linear increase in $W$ with time and using the mixing time-scale $\tau$ of the preindustrial steady state balance calculated above ( $54 \mathrm{yr}$ ). The simple model given by (20) seems to be a good predictor of the water cycle change with the best fit of predicted $\int F_{w}^{\prime} d t$ to the "real" $\int F_{w}^{\prime} d t$ being reached using a slightly larger $\tau$ of $58 \mathrm{yr}$.

\section{Discussion and conclusions}

Here we have used the water-mass transformation framework to describe the relationship between the salinity distribution of the global ocean and the water cycle. We show how, in order to maintain the salinity distribution in steady state, the water cycle must involve net evaporation over high-salinity regions of the ocean and net precipitation and river runoff over low-salinity regions. Using observed salinity and estimates of evaporation, precipitation, and river runoff, we find that the salinity distribution is maintained by transfer of approximately $2.7 \mathrm{~Sv}$ of freshwater from high-salinity to low-salinity regions.

Using the water-mass transformation framework, we develop a simple model for the evolution of the mean deviation of salinity using a fixed mixing time scale. Using the observed salinity distribution the time scale is estimated to be of the order of $50 \mathrm{yr}$. A state-of-the-art climate model is found to have an equivalent time scale describing its quasi-steady state. The same model's water cycle evolves according the simple model with a mixing time scale within $10 \%$ of that derived from its quasi-steady state.
This study provides a proof of concept for relating the broadening of the salinity distribution to changes in the water cycle. However, a number of limitations must be highlighted:

- Regional changes in the water cycle cannot be identified using the mean deviation of the salinity distribution alone. It may be possible to exploit the multiple peaks in the salinity distribution and links to the interbasin circulation to this end.

- The simple model [see (16)] with a time-invariant mixing time-scale $\tau$ does not account for dynamical responses to ocean circulation and consequent mixing rates that may occur in a changing climate (e.g., as a result of changes in wind, thermal, and haline forcing). This may explain the lack of correspondence between the predicted water cycle change and the actual water cycle change in CCSM4 over the first half of the twenty-first century (Fig. 4c).

- The use of the accumulated $P-E+R$ integrated over salinity classes $F_{w}$ as a metric for the water cycle may obscure changes in the geographical pattern of $P-E+R$ and/or changes in the location of high- and low-salinity regions.

These caveats and their implications for relating observed salinity changes to changes in the hydrological cycle will be explored in future work.

Acknowledgments. This research was supported by the Natural Environment Research Council (NERC). We thank Drs. Adam Blaker, Jeremy Grist, Bablu Sinha, and Magnus Hieronymus as well as two anonymous reviewers for their helpful comments on this manuscript. We are grateful to the Met Office and Dr. Paul Durack for making their salinity data available and to the developers of CCSM4. Computations were performed on the TCS supercomputer at the SciNet HPC Consortium. SciNet is funded by the Canada Foundation for Innovation under the auspices of Compute Canada, the government of Ontario, Ontario Research Fund-Research Excellence, and the University of Toronto.

\section{APPENDIX A}

\section{The Effect of Surface Salt Fluxes Compared with Surface Freshwater Fluxes}

In many ocean models the surface freshwater flux is represented as a flux of salt rather than actual water (in reality, precipitation, river runoff, and ice do have nonzero quantities of salt). In such a case the volume balance given in (4) becomes 


$$
\frac{d V\left(S^{*}\right)}{d t}=-G\left(S^{*}\right)
$$

In this approximation the salt flux at the ocean surface is represented by a reference salinity $S_{0}$ multiplied by $P-E+R$. Hence, the salt balance found in (6) becomes

$$
\frac{d \mathbb{S}\left(S^{*}\right)}{d t}=-F_{w}\left(S^{*}\right) S_{0}-S^{*} G\left(S^{*}\right)+D\left(S^{*}\right) .
$$

Combining (A2) and (A1) we yield an equivalent form of (8):

$\frac{d \mathbb{S}\left(S^{*}\right)}{d t}=-S_{0} F_{w}\left(S^{*}\right)-S^{*} \frac{d V\left(S^{*}\right)}{d t}+D\left(S^{*}\right)$.

The surface salt flux case (A3) is identical to the surface freshwater flux case (8) at $S^{*}=\bar{S}$ and where $S_{0}=\bar{S}$ is chosen. Hence, the theory described in section 3 holds for both cases.

\section{APPENDIX B}

\section{The Effect of Variations in the Total Volume of the Ocean}

In section 3 we derive the following formula relating the width of the salinity distribution to the volume of water less than the mean salinity $V(\bar{S})$ and the salt contained therein $\mathbb{S}(\bar{S})$ :

$$
W=\frac{2}{V_{0}}[\bar{S} V(\bar{S})-\mathbb{S}(\bar{S})] .
$$

If, over time, there is a flux of freshwater into the ocean (e.g., as a result of melting glaciers), the volume of the ocean changes, as does the mean salinity (we will not consider the case where the total salt content $\mathbb{S}\left(S_{\max }\right)$ changes-relevant on geological time scales). Hence, the time derivative of (B1) yields

$$
\begin{aligned}
\frac{d W}{d t}= & 2 \frac{d}{d t} \frac{1}{V_{0}}[\bar{S} V(\bar{S})-\mathbb{S}(\bar{S})]+\frac{2}{V_{0}} \frac{d \bar{S}}{d t} V(\bar{S}) \\
& +\frac{2 \bar{S}}{V_{0}} F_{w}(\bar{S})-\frac{2}{V_{0}} D(\bar{S}) .
\end{aligned}
$$

Above, the first two terms are due to the rate of change of $\bar{S}$ and $V_{0}$. The last two terms are identical to the righthand side of (14). Since $\bar{S}=\mathbb{S}\left(S_{\max }\right) / V_{0}$, (B2) becomes

$$
\frac{d W}{d t}=-2 \frac{d V_{0}}{d t}\left[\frac{2 \bar{S} V(\bar{S})}{V_{0}^{2}}-\frac{\mathbb{S}(\bar{S})}{V_{0}^{2}}\right]+\frac{2 \bar{S}}{V_{0}} F_{w}(\bar{S})-\frac{2}{V_{0}} D(\bar{S}) .
$$

Since the salinity distribution is approximately symmetric and $\bar{S}$ is large relative to $W$, we apply the following approximations:

$$
2 V(\bar{S}) \approx V_{0} ; \quad 2 \mathbb{S}(\bar{S}) \approx \mathbb{S}\left(S_{\max }\right) .
$$

Hence, (B3) becomes

$$
\frac{d W}{d t}+\frac{d V_{0}}{d t} \frac{\bar{S}}{V_{0}} \approx \frac{2 \bar{S}}{V_{0}} F_{w}(\bar{S})-\frac{2}{V_{0}} D(\bar{S}),
$$

or, alternatively,

$$
\frac{d W}{d t}-\frac{d \bar{S}}{d t} \approx \frac{2 \bar{S}}{V_{0}} F_{w}(\bar{S})-\frac{2}{V_{0}} D(\bar{S}) .
$$

If the ocean is gaining mass, $F_{w}(\bar{S})$ will represent changes in both the hydrological cycle and freshwater input. If this freshwater input were equally partitioned between both the saline and fresh sides of the distribution, then the "water cycle" could be defined as

$$
F_{\text {cycle }}=F_{w}(\bar{S})-\frac{1}{2} \frac{d V_{0}}{d t} .
$$

In this case (B5) becomes

$$
\frac{d W}{d t} \approx \frac{2 \bar{S}}{V_{0}} F_{\text {cycle }}-\frac{2}{V_{0}} D(\bar{S}) .
$$

Hence, (14) may hold even in the presence of net freshwater input. If the net freshwater input occurred where the ocean is fresher than average (e.g., in the case of high-latitude glacial melt), one could define the change in the water cycle as

$$
F_{\text {cycle }}=F_{w}(\bar{S})-\frac{d V_{0}}{d t} .
$$

In this case (B6) can be written as

$$
\frac{d W}{d t}+\frac{d \bar{S}}{d t} \approx \frac{2 \bar{S}}{V_{0}} F_{\text {cycle }}-\frac{2}{V_{0}} D(\bar{S}) .
$$

Although the effect of increases in ocean volume $d V_{0} / d t$ adds complexity to the model for the salinity distribution, this volume change is regularly estimated. Considering the climate change experiment discussed in section 5b, a typical year-2100 sea level rise of $20 \mathrm{~cm}$ as a result of mass input (i.e., excluding thermal expansion, which does not affect salinity) would imply that $d V_{0} / d t \approx$ $0.02 \mathrm{~Sv}$, and hence $d \bar{S} / d t \approx 0.02 \mathrm{~g} \mathrm{~kg}^{-1}(100 \mathrm{yr})^{-1}$. This is $10 \%$ of the rate of change of $W$ in CCSM 4 , implying that the change in total ocean volume can have a quantitative impact on the diagnosis of the water cycle, particularly if 
the total freshwater input is on one side of the salinity distribution.

\section{REFERENCES}

Boyer, T. P., and Coauthors, 2006: World Ocean Database 2005. NOAA Atlas NESDIS 60, 190 pp.

Dai, A., and K. E. Trenberth, 2002: Estimates of freshwater discharge from continents: Latitudinal and seasonal variations. J. Hydrometeor., 3, 660-687, doi:10.1175/ 1525-7541(2002)003<0660:EOFDFC > 2.0.CO;2.

— T. Qian, K. E. Trenberth, and J. D. Milliman, 2009: Changes in continental freshwater discharge from 1948 to 2004. J. Climate, 22, 2773-2792, doi:10.1175/2008JCLI2592.1.

Durack, P. J., and S. E. Wijffels, 2010: Fifty-year trends in global ocean salinities and their relationship to broad-scale warming. J. Climate, 23, 4342-4362, doi:10.1175/2010JCLI3377.1.

_ _ _ _ and R. J. Matear, 2012: Ocean salinities reveal strong global water cycle intensification during 1950 to 2000. Science, 336, 455-458, doi:10.1126/science.1212222.

Evans, D. G., J. D. Zika, A. C. Naveira Garabato, and A. Nurser, 2014: The imprint of Southern Ocean overturning on seasonal water mass variability in Drake Passage. J. Geophys. Res. Oceans, 119, 7987-8010, doi:10.1002/2014JC010097.

Gent, P. R., and Coauthors, 2011: The Community Climate System Model version 4. J. Climate, 24, 4973-4991, doi:10.1175/ 2011JCLI4083.1.

Groeskamp, S., J. D. Zika, T. J. McDougall, B. M. Sloyan, and F. Laliberté, 2014: The representation of ocean circulation and variability in thermodynamic coordinates. J. Phys. Oceanogr., 44, 1735-1750, doi:10.1175/JPO-D-13-0213.1.

Held, I. M., and B. J. Soden, 2006: Robust responses of the hydrological cycle to global warming. J. Climate, 19, 5686-5699, doi:10.1175/JCLI3990.1.

Helm, K. P., N. L. Bindoff, and J. A. Church, 2010: Changes in the global hydrological-cycle inferred from ocean salinity. Geophys. Res. Lett., 37, L18701, doi:10.1029/2010GL044222.

Hieronymus, M., J. Nilsson, and J. Nycander, 2014: Water mass transformation in salinity-temperature space. J. Phys. Oceanogr., 44, 2547-2568, doi:10.1175/JPO-D-13-0257.1.

Hosoda, S., T. Suga, N. Shikama, and K. Mizuno, 2009: Global surface layer salinity change detected by Argo and its implication for hydrological cycle intensification. J. Oceanogr., 65, 579-586, doi:10.1007/s10872-009-0049-1.

Huffman, G. J., R. F. Adler, D. T. Bolvin, and G. Gu, 2009: Improving the global precipitation record: GPCP version 2.1 . Geophys. Res. Lett., 36, L17808, doi:10.1029/2009GL040000.

Ingleby, B., and M. Huddleston, 2007: Quality control of ocean temperature and salinity profiles-Historical and real-time data. J. Mar. Syst., 65, 158-175, doi:10.1016/j.jmarsys.2005.11.019.

Josey, S. A., S. Gulev, and L. Yu, 2013: Exchanges through the ocean surface. Ocean Circulation and Climate: A 21st Century
Perspective, 2nd ed. G. Siedler et al., Eds., International Geophysics Series, Vol. 103, Academic Press, 115-140.

Large, W., and S. Yeager, 2009: The global climatology of an interannually varying air-sea flux data set. Climate Dyn., 33, 341-364, doi:10.1007/s00382-008-0441-3.

McDougall, T. J., D. R. Jackett, and F. J. Millero, 2009: An algorithm for estimating absolute salinity in the global ocean. Ocean Sci. Discuss., 6, 215-242, doi:10.5194/osd-6-215-2009.

Mudryk, L., P. Kushner, and C. Derksen, 2014: Interpreting observed Northern Hemisphere snow trends with large ensembles of climate simulations. Climate Dyn., 43, 345-359, doi:10.1007/s00382-013-1954-y.

Peixoto, J. P., and H. A. Oort, 1992: Physics of Climate. American Institute of Physics, 520 pp.

Schanze, J. J., R. W. Schmitt, and L. Yu, 2010: The global oceanic freshwater cycle: A state-of-the-art quantification. J. Mar. Res., 68, 569-595, doi:10.1357/002224010794657164.

Skliris, N., R. Marsh, S. A. Josey, S. A. Good, C. Liu, and R. P. Allan, 2014: Salinity changes in the World Ocean since 1950 in relation to changing surface freshwater fluxes. Climate Dyn., 43, 709-736, doi:10.1007/s00382-014-2131-7.

Taylor, K. E., R. J. Stouffer, and G. A. Meehl, 2012: An overview of CMIP5 and the experiment design. Bull. Amer. Meteor. Soc., 93, 485-498, doi:10.1175/BAMS-D-11-00094.1.

Trenberth, K. E., L. Smith, T. Qian, A. Dai, and J. Fasullo, 2007: Estimates of the global water budget and its annual cycle using observational and model data. J. Hydrometeor., 8, 758-769, doi:10.1175/JHM600.1.

__ J. T. Fasullo, and J. Mackaro, 2011: Atmospheric moisture transports from ocean to land and global energy flows in reanalyses. J. Climate, 24, 4907-4924, doi:10.1175/ 2011JCLI4171.1.

Walin, G., 1977: A theoretical framework for the description of estuaries. Tellus, 29A, 128-136, doi:10.1111/ j.2153-3490.1977.tb00716.x.

_ 1982: On the relation between sea-surface heat flow and thermal circulation in the ocean. Tellus, 34A, 187-195, doi:10.1111/j.2153-3490.1982.tb01806.x.

Wilson, J., 1998: Global Temperature-Salinity Profile Programme (GTSPP)-Overview and future. Intergovernmental Oceanographic Commission Tech. Doc. 49, 33 pp. [Available online at http://unesdoc.unesco.org/images/0011/001139/113964Eo.pdf.]

Xie, P., and P. A. Arkin, 1997: Global precipitation: A 17-year monthly analysis based on gauge observations, satellite estimates, and numerical model outputs. Bull. Amer. Meteor. Soc., 78, 2539-2558, doi:10.1175/1520-0477(1997)078<2539: GPAYMA $>2.0 . \mathrm{CO} ; 2$.

Yu, L., and R. A. Weller, 2007: Objectively analyzed air-sea heat fluxes for the global ice-free oceans (1981-2005). Bull. Amer. Meteor. Soc., 88, 527-539, doi:10.1175/BAMS-88-4-527.

Zika, J. D., M. H. England, and W. P. Sijp, 2012: The ocean circulation in thermohaline coordinates. J. Phys. Oceanogr., 42 , 708-724, doi:10.1175/JPO-D-11-0139.1. 